\title{
Roadblocks to Responsible Innovation: Exploring technology assessment and adoption in U.S. Public Highway Construction
}

\begin{abstract}
U.S. Public Highway Construction Industry professionals are responsible for assessing and adopting new technology that can improve the cost and quality of roadways. This paper investigates features of the technology assessment and adoption process in the U.S. public highway construction industry that both facilitate and hinder responsible innovation. Often technological innovations are incongruent with current specifications, i.e., regulatory construction standards, whereby specification reform serves as a precursor to implementation. We examine this aspect of technology assessment and adoption through a novel application of Kingdon's theory of policy agenda setting to a highly technical state bureaucratic institution using a case study on Intelligent Compaction. Specification reform relating to Intelligent Compaction is occurring in nearly a quarter of U.S. states. Analysis of interviews with industry professionals revealed that institutional incentives for supporting innovations were not the main drivers for adoption, and there exists a conservative culture that inhibits change. Individuals that go against this grain by championing change do so based on their personal character, ideological affiliations and a perceived sense of social obligation, which coincides with the principles set forth in the responsible research and innovation literature. These individuals, whom we identify as Kingdon's policy entrepreneurs, appear to present themselves in four roles in this industry: explorer, pioneer, gatekeeper, and leader. Our findings indicate that alignment of these roles creates an environment conducive to responsible technology assessment and adoption, and therefore greater societal benefit. Ultimately, we hope this study will benefit U.S. Highway Construction Industry regulatory environments by enhancing identification of specification processes, key roles, and personal/ethical ideologies that may be conducive to fostering a culture of responsible innovation.
\end{abstract}

\section{Introduction}

The condition of the United States highway system is deteriorating, with only $50 \%$ of roads in good condition, according to a recent report by the American Association of State Highway and Transportation Officials (AASHTO) [1]. The problem impacts not only state transportation budgets, but also individual motorists who spend on average \$355 annually on vehicle maintenance due to poor road conditions [1]. One primary way to relieve this problem is for technological innovation to deliver faster, cheaper, and higher quality road construction [2]. However, the public road construction sector is notoriously resistant to adopting innovative technologies [3]. Technology assessment and adoption in 
road construction requires a delicate balance between public safety and risk, under relentless fiscal constraints.

This study extends the consideration of technology assessment and adoption, which has been the focus of investigation within a number of industries, including agro-food [4], clean energy [5,6] and wastewater treatment [7], to the field of highway construction. The highway construction industry presents a particularly compelling site for investigating technology assessment and adoption because (a) policy reform occurs concurrently with technology assessment and adoption - embodied by the drafting and adoption of new construction specifications, even for experimental pilot projects, and (b) the industry is highly technical, bureaucratically decentralized, and risk averse. These characteristics create a charged policy environment that faces significant hurdles in harnessing technological improvement to produce social benefits.

In order to investigate this challenging confluence of technology assessment and adoption and policy making, we engage Kingdon's [8] theory of public policy agenda setting, as demonstrated in the literature (e.g., [9-11]) to be a powerful tool for understanding policy reform. Given that much of the literature addressing agenda setting has focused on politicized issues at the federal level [e.g., [9-11], this application of Kingdon's theory to a highly technical and bureaucratically decentralized industry represents a novel contribution. Transportation technology policy making in the US is bureaucratically decentralized, with most technology decisions occurring at a state, and even district level. State DOT's employ a majority of technical positions, and encourage the hiring of engineers into non-engineering roles, resulting in a highly technical workforce [12]. Scholars have suggested that Kingdon's theory may be applied to such technical decision making environments, referred to as scientific-bureaucratic institutions, but have only looked at federal systems in the US [9]. Furthermore, the risk-averse nature of the highway construction industry poses considerable challenges to technology assessment and adoption, in large part due to inherent uncertainty and potential disruptions of social institutions and critical infrastructure [4]. The highway construction industry struggles particularly with emerging technologies, which are the single largest contributor to risk at a project level [13].

In addition, we analyze the behavior of professionals in this risk-averse environment by applying concepts from the burgeoning field of Responsible Research and Innovation (RRI), which considers risks and potential rewards in the context of perceived ethical motivations and societal obligations of professionals [14]. Expanding the occupational role of engineers to include socially responsible policy making is a hallmark of responsible innovation literature [15], but in practice, this expansion faces cultural barriers from the profession $[3,16]$. The highway construction industry provides an excellent opportunity to study these tensions, testing the limits of RRI in a significant way. 
This paper expands on a case study of intelligent compaction (IC) [17], discussing technology assessment and adoption processes in the highway construction sector. IC is an emerging technology for soil compaction quality assurance (QA) at various stages of adoption across the United States. IC requires the adoption of new specification policies in order to be implemented, even in the case of pilot projects. In these situations, departments of transportation (DOTs) must employ simultaneous technology assessment and policy reform to drive adoption.

Our data emerge from semi-structured interviews of industry professionals and academics and a review of technical literature. We consider the practical impact of IC on the highway construction community, in the context of owners, contractors and end-users. We are able to classify the dynamic processes of technology assessment and adoption, identify the roles of key players in the diffusion process and illuminate the critical resources and personality traits that make these players influential.

Our paper begins with an overview of Kingdon's theory. We then provide a succinct description of IC, followed by a section explaining highway construction specifications and the organizational structure of this industry. Additionally, we detail the formal process by which specifications are changed. The third section ties together the case study and Kingdon's theory by defining the critical components of Kingdon's policy agenda setting theory in the context of highway construction specification reform. The fourth section discusses the methodology and analysis underlying this study. The final section presents insights gained through the application of Kingdon's framework and RRI concepts to the key people and processes that have played a part in the diffusion of IC.

\section{Kingdon's Theory of Public Policy Making}

Scholars and other external observers have sought to understand the manner by which public policy manifests change (e.g., [18]). Perhaps the most widely used framework in this area is John Kingdon's Agendas, Alternatives, and Public Policies [8], which presents a formalized approach to analyzing policy reform activities. Kingdon begins by identifying the plethora of topics associated with a given domain, which individually may or may not be paid serious attention. Of particular interest is the narrowing process by which specific issues and initiatives become selected to a decision agenda from what could otherwise be described as an infinite realm of possibilities. Kingdon's theory of public policy making establishes a framework that enables us to understand and identify the motivations and drivers behind setting the decision agenda within a given institution.

Kingdon's theoretical framework describes public policy agenda setting as a confluence of three streams: problem definition, policy solutions, and political environment. A problem must be defined to attract sufficient attention and ultimately warrant resolution. A number of policy solutions may evolve that fit certain criteria including demonstrating technical feasibility and aligning with specific problem 
related values. Finally, the prevailing political environment must be conducive to changes in the domain in question [10].

Kingdon's stream analogy exemplifies the dynamism associated with each of the three components of policy formulation. These processes develop and evolve coincidentally rather than according to a formal or linear progression [10], as borrowed from the Garbage Can model of Cohen et. al. [19]. Policy reform results from streaming confluence under a window of opportunity opened by both specific causality as well as probabilistic serendipity [18].

Kingdon conceptualizes the interaction of three streams in the context of decision agenda-setting and policy making at the federal level of US Government. Scholars have suggested that Kingdon's framework may, however, apply more generally to all policy environments. Kingdon's analysis approach has been applied to policy environments such as state legislative bodies (e.g., [11]) and federal scientificbureaucratic institutions [9]. In nearly all cases, authors have ultimately identified theoretical limitations with respect to specific application outside Kingdon's original lens.

\section{Intelligent Compaction}

Intelligent Compaction is a technology used for monitoring soil compaction quality during soil compaction. We first describe the traditional practice of soil compaction and specification thereof that is common to nearly every highway project. We then explain how IC changes this activity - not just by adding a new tool, but by improving efficiency and quality of roadway construction.

Every structure that interfaces with the earth must have a mechanically stable foundation. Roadways typically use compacted soil for this foundation. While there are several practices for compacting soil, highway construction often uses roller compactors (see Figure 1) because of the speed with which they can compact large tracts of soil. On a highway construction project, soil compaction must meet certain specifications that seek to ensure a mechanically stable structure.

Figure 1. Example of a roller compactor used on highway projects. [20]

The specification of soil compaction is not entirely straightforward, due to the complex nature of soil. Highway design engineers specify foundations in terms of "stiffness." Soil stiffness reflects the resistance to vertical deflection under a given load or stress, and is measured in units of stress or force over deflection. Stiffness development through compaction is particularly important to ensure the mechanical stability of highway subgrade materials, as they are subject to repetitive traffic loading [21]. Due to soil's mechanical complexity, there is a multitude of ways to define its stiffness, only a few of which are used in pavement design (e.g., resilient or elastic modulus). A modulus value, however, is 
notoriously challenging to quantify in the field. IC presents one of the first opportunities to quantify the in-situ stiffness of a soil.

In current earthwork construction, soil compaction is typically specified in terms of target density and water content (per ASTM D698 [22]), based on the assumption that there is a phenomenological correlation between these parameters and modulus. The relationship between modulus and density/ water content is not fully understood, leaving an unresolved discrepancy between design, construction specifications, and operational performance.

There are several technologies for evaluating soil compaction. The most widely used are the Nuclear Density Gauge and Sand Cone (ASTM D5195-14 and ASTM D1556-07), which measure density and water content at discrete locations on the roadway. These methodologies provide less than $0.1 \%$ spatial coverage of the constructed soil layer, and require stoppage of construction activities that can lead to considerable delays [23]. Poor spatial coverage can lead to acceptance despite the presence of areas with insufficient compaction or water content. Contractors attempt to avoid construction delays at all costs and generally perceive soil compaction monitoring as a hindrance to progress.

IC is a machine-integrated soil compaction evaluation method that reports in real-time during construction. IC vastly improves coverage of soil testing (i.e., from $<0.1 \%$ to virtually $100 \%$ ) [24] ensuring a more comprehensive performance evaluation. Furthermore, IC provides real-time measurements, eliminating the delays associated with conventional spot testing techniques.

Many IC systems, including those for vibratory compaction, are correlated to the stiffness of the soil, which is more congruent with mechanistic design characteristics. One problem is that the stiffness measurements provided by these systems are not standardized between manufacturers. Each IC manufacturer has a proprietary stiffness measurement value that does not replicate any widely used stiffness parameter [25]. This lack of standardization requires site specific calibration of IC and complicates the provision of standardized specifications for IC [25-28]. In effect, technology innovation (i.e., IC) requires policy innovation (i.e., a standard for stiffness measurement values that cross technological platforms). IC for vibratory compaction thus represents both a change in process and measurement quantity of a QA program specification.

Such dramatic procedural change can encounter significant resistance with respect to an institutional status quo. A NCHRP study [29] on the culture within the highway construction sector reported that institutional inertia poses a considerable barrier to innovation. This report goes on to say that several factors such as risk, economy and quality can serve to either enhance or inhibit such a process conversion.

In Colorado for example, the CDOT Field Materials Manual states that there is no intention to discourage contractors from developing and/or implementing 'better or faster methods of testing' [30] than 
those suggested as acceptable QA protocol or technologies. CDOT by no means, however, provides incentive to develop new testing technologies and in fact requires a complicated and rigorous approval process by both independent and federal regulatory committees [30]. This paper identifies specific pathways by which IC has begun to diffuse into becoming an accepted performance evaluation technology for QA program specification.

\subsection{Highway Construction Specifications}

Specifications are the primary method used by highway construction project owners to ensure that the desired level of quality of construction is achieved. Simultaneously, specifications can be barriers to innovation because of their rigidity. Here we define specifications in the context of highway construction projects and the process by which they can be changed, e.g., to allow for the adoption of an innovation. We also discuss the key players in the highway construction industry that help shape these policies.

Construction specifications provide the basis for performance evaluation, and serve as a crucial link between a construction project owner (State DOT) and construction contractor. They are coincident to all infrastructure projects, typically involving the development of a Quality Assurance (QA) Program [30]. Through QA programs, 'materials, products, and workmanship' [30] are ensured to meet specifications by providing evidence and documentation for both acceptance and archival purposes [30]. Statewide manuals outline specifications that dictate almost every aspect of a project from the types of soils and concrete mixes used, to the spacing of rebar in bridges, to the degree of compaction of each layer of a roadway, etc.

There are several key players in the highway construction arena, as shown in Figure 2, all of whom contribute to specification formation and implementation. State DOTs are the majority owners of almost all highway construction projects, and as such set and maintain the current specifications. Proposed changes to the current specifications must pass DOT review, in addition to review by several external parties. Supplementary funding for highways is often provided by the Federal Highway Administration (FHWA), giving them the power to review specification changes. Each state has local chapters of the Associated General Contractors (AGC) of America that represent the interests of the contractors in a given state. The AGC is consulted to ensure that new specifications are not too onerous on contractors. In the case of special specifications, the construction contractor on the project is a key player in shaping the new policy. Other parties may play various roles on a case-by-case basis, such as academic consultants, private financial investors, etc.

Figure 2. Structure of highway construction specification formation and implementation. 
The state DOTs are the most important players in specification reform, often initiating reform as well as passing new policies. Therefore, it is critical to understand the state DOTs' decentralized organizational structure. State DOT organization is similar across the United States, with only minor variations from state to state. The DOTs geographically split their state into several districts that are run by district offices. These offices manage the majority of roadway construction projects, with the exception of special projects (e.g., large or complicated projects) that are managed by the central office. The central office handles specifications, research, and funding distribution. While the district offices receive funding from the central office, they have the freedom to manage projects largely at their own discretion; although these district offices will, at times, request technical guidance from the central office, for example, in the case of innovative technologies. As we will demonstrate, this operational independence turns out to be an important feature when considering the diffusion of innovation.

Certain innovations, such as IC, are incompatible with current statewide construction specifications and require specification reform for implementation. New specifications are introduced in two phases: project specific pilot or special specifications and statewide specifications. Special specifications are a way to trial a new form of specification while limiting the risk of failure to a single project. These specifications may even be introduced as shadow specifications that are implemented in addition to existing specifications to further limit risk. Multiple special specifications may be created within a single state for a given innovation until a document general and successful enough emerges and can be adopted for statewide specification reform. Statewide specification revision differs in frequency from state to state, ranging from 1 year to 10 years. Both special and statewide specifications must be approved via a specification review committee, composed of high level officials including chief engineers and division heads.

To our knowledge, IC has yet to pass statewide specifications in any state, but special specifications for IC exist in at least 10 states. As a result, this research focuses mostly on the passage of special specifications, the crucial first step for any emerging technology in highway construction.

\section{Defining Kingdon's Framework in Highway Construction}

In order to gain insights into the technology assessment and adoption process in the highway construction industry, we can apply Kingdon's framework to specification reform for IC. This section defines the critical components of Kingdon's framework as they apply to this case study. The problem, policy, and political streams are described, as well as policy entrepreneurs and the joining of the streams.

\subsection{Problem Stream}


Kingdon posits that problems are defined or punctuated in response to conditions that violate social values [11]. Due to the rather compartmentalized nature of the US highway construction sector, i.e., individual state DOT dominance, value identification and consensus is far from widespread. With respect to specific values, the emergence and diffusion of IC is largely in response to perceived problems with regard to product uniformity, design specification conformity, budgetary economy, and construction quality. In fact, a particular challenge in the highway construction industry is that the interpretation of these values is largely subjective. IC provides a solution that implies a particular problem that may or may not exist, depending upon whom you ask.

Kingdon conceptualizes how a problem may be defined by discussing several indicators [8]. Among others, problem punctuation by formal study is particularly appropriate to consider in the IC case study. He notes that research studies often serve to quantify the actual magnitude of a problem. Studies performed by academic, governmental, or non-government agencies can better characterize how the problem is defined and how significant it may or may not be. Kingdon specifically cites the effectiveness of systematic engineering studies in the case of highway and bridge repair ([8], p. 91).

With regards to soil compaction, there are no comprehensive studies quantifying the impact of conventional spot testing methods on highway lifecycle costs and quality. It is generally accepted that soil's heterogeneity can lead to considerable spatial variations in compaction, and that poor compaction leads to reduced roadway performance in the form of potholes, cracking, and other failures. Studies on IC have repeatedly shown the level of soil compaction to vary widely within test sites. Practitioners will admit that spot testing is highly sensitive to location. However, the extent to which monitoring related occurrences of sub-par soil compaction lead to decreased performance has not been established.

The lack of a universally accepted assessment of the perceived problem associated with IC adoption critically impacts problem stream development among key players. Kingdon acknowledges that a lack of values consensus can at times trump even scientific evidence or documentation of a viable policy alternative. Our research has specifically targeted problem punctuation mechanisms in the case of IC. Additionally, the relationship between values consensus and personal character with respect to problem punctuation is evaluated.

\subsection{Policy Stream}

Kingdon describes a policy "primeval soup," ([8], p.116) in which many undeveloped ideas coexist, evolving until one or more policy alternatives gain prominence. These ideas are created by specialists within the "policy community", ([8], p. 117). The criteria for survival is based on their

"technical feasibility" ([8], p.131) and "value acceptability" ([8], p.132), among other things [8]. Here we discuss idea generation and survival as it pertains to highway construction. 
Idea generation in the highway construction policy community occurs hand-in-hand with the evaluation of technical feasibility, typically via research studies. These research studies, almost always conducted via pilot implementations, not only provide scientific evaluation of various policy ideas, many go so far as to provide explicit policy recommendations. In this regard, pilot studies become the most active contributors in the "primeval soup". For example, one of the most comprehensive research papers on IC listed as its second overall goal to provide "recommendations for using the compaction monitoring technology in practice" [26]. In another example, researchers state "Field spot tests are essential to IC implementation to provide correlation to IC measurements" [27], and go on to suggest methodologies for these correlations. The FHWA, a main funder of IC research projects, provided an example specification based on research they funded [28]. While these reports are building blocks for future policy, Kingdon's analogy of a primeval soup fittingly describes the evolutionary process by which finalized policies are formed.

While formation of IC policies in the primeval soup center on technical feasibility, values-based negotiations are still very much a part of the process, perhaps trumping technical consideration in many cases. In IC policy, there are several points on which key players may disagree, including: calibration frequency and method, percent coverage that must pass a certain threshold, and the value of that threshold. Multiple solutions may have similar enough technical validity, ultimately resulting in a valuesbased decision making process.

\subsection{Political Stream}

The political stream describes the propensity for policy change in the current political environment. In Kingdon's analysis of federal legislative bodies, political environment typically refers to the distribution of political party affiliation [8]. However, he notes that this is not an exclusive interpretation of political environment, and in fact, within transportation regulation there is a distinct lack of political party affiliation. In this paper, we investigate surrogate ideological affiliations that may guide decision making processes.

In his theoretical formulation at the federal level, Kingdon locates primary decision-making authority with political appointees. He prescribes only minor decision support to civil servants. However, in highly technical institutions such as DOTs it is possible that the balance of power between political appointees and civil servants may be distributed differently.

\subsection{Policy Entrepreneurs}

Policy entrepreneurs serve to raise awareness and garner support for issues, problems, and solutions within the surrounding network. Policy entrepreneurs are ultimately responsible for orchestrating the alignment of Kingdon's three streams. Kingdon identifies three categories of incentives 
pursuant of the entrepreneur: (1) personal interest, (2) values promotion, and (3) pure enjoyment of the game [8]. Kingdon does not, however, discuss which incentives may be more or less likely to prevail in a given policy arena. Interestingly, it appears that the values promotion category of policy entrepreneur exemplifies many attributes associated with RRI literature, namely a strong ethical commitment to maximizing societal benefit $[14-16,18]$.

Kingdon rightly identifies the critical role of the policy entrepreneur in the agenda setting process. The framework may however underappreciate inequalities in power and resources between various stakeholders and policy entrepreneurs assuming roles at different locations within a network. For example, Blackman [31] discusses the disproportionate weighting of financial power in the context of the tobacco industry lobby at state level. Further, Kingdon's theory does not characterize the different roles that policy entrepreneurs may assume with respect to their allocated resources. Interestingly, the IC case study identifies entrepreneurs at different levels of the network with markedly different roles and resources.

\subsection{Joining the Streams}

Policy issues reach the decision agenda via policy windows that are opened during the confluence of the three streams. According to Kingdon, the opening of these windows is due to a combination of serendipity and influence of policy entrepreneurs.

Kingdon ([8], p. 20) notes that the three streams typically couple during brief windows of opportunity. Kingdon suggests two primary mechanisms by which final stream coupling may occur, either via problem or political motivated policy windows. Problems may suddenly capture the attention of political figures, thereby pushing it into the forefront of decision making agendas. Conversely, a notable shift in the political stream, such as a turnover of administrations, can provide the alignment and momentum change necessary to open a policy window. We investigate the presence of both types of policy windows in our paper.

According to Kingdon, the three streams exhibit a dynamism that evolves independently and coincidentally to one another, coupling only at critical moments [31]. Several authors have noted a more connected relationship between stream developments. Kelly [11], applying the framework via examination of state level policy related to public schools, noted that state legislative bodies are not free to act as autonomously as federal entities, indicating that a purely independent development of the three streams is questionable. Harrison et. al. [9] found that for scientific-bureaucratic institutions, the problem and political streams exhibited a high degree of overlap. This study, in fact, identifies a strong coupling between the problem and policy streams.

Indeed, the confluence of the three streams relies upon several factors that vary with specific instance. One component, however, seems rather universal to bolstering convergence: the role of the 
policy entrepreneur. Nearly all of the supporting literature has identified the critical importance of individual champions within institutions to initiate various activities that ultimately coalesce to drive policy innovation (e.g., [11], etc.). Policy entrepreneurs exert their time, energy, reputation, and money to join together the three agenda-setting streams.

\section{Methodology}

We conducted interviews in order to investigate causal relationships and key players in the policy reform and innovation diffusion process. Interviewees included members from several state DOTs, comprising employees from both central and district offices, FHWA officials, construction contractors, and $\mathrm{QC} / \mathrm{QA}$ contractors. The position of interviewees ranged from project managers, to research engineers, to materials engineers. Participants were initially selected by cold calling individuals connected to intelligent compaction by technical reports. Additional participants were identified in a snowball fashion, whereby interviewees were asked to suggest other candidates from their professional network. The process was considered complete once we had collected data from participants at all affiliations deemed important by the interviewees. Additionally, at this point, conclusions drawn from interview materials tended to converge.

Interviews were conducted face-to-face and over the phone, typically lasting about an hour. A predetermined set of questions was asked first (given in Appendix A), with the remainder of the interview being a free-form discussion allowing participants to direct the conversation into rich areas. All interviews were recorded for analysis purposes and coded using Dedoose (see www.dedoose.com). Dedoose is an online qualitative data analysis tool. We used this tool to facilitate the organization and quantification of interview results.

In all, eleven participants were interviewed. The demographics of the participants are presented in Table 1. It can be seen that there is a wide range of education levels, affiliations, positions, and years of experience captured by this group of participants. Interview participants consisted of 10 males and 1 female. Congruent with Schachter [32], the transportation industry is noted to be a male dominated field. The majority of this study's participants had college level education. With regards to participant affiliation, a relatively large number of DOT officials were interviewed because the DOTs control the regulation process. As this is a case study on QC of constructed materials, we interviewed a majority of materials engineers. It is worth noting that research engineers are also concerned with advancing the practice of materials engineering. A professional engineering (PE) license is an important distinction to hold in this industry, which is why all but one participant was a PE. Finally, the demographics of the interview participants indicate that people tend to have long tenure in the industry.

Table 1. Demographics of interview participants. 


\begin{tabular}{|c|c|c|}
\hline Category & Trait & Quantity \\
\hline \multirow[t]{2}{*}{ Sex } & Male & 10 \\
\hline & Female & 1 \\
\hline \multirow[t]{4}{*}{ Education } & High School & 1 \\
\hline & Bachelors & 4 \\
\hline & Masters & 5 \\
\hline & Ph.D. & 1 \\
\hline \multirow[t]{4}{*}{ Affiliation } & FHWA & 1 \\
\hline & DOT & 6 \\
\hline & Municipality & 1 \\
\hline & Contractor & 3 \\
\hline \multirow[t]{4}{*}{ Position } & Materials Engineer & 5 \\
\hline & $\mathrm{QC} / \mathrm{QA}$ & 3 \\
\hline & Research Engineer & 2 \\
\hline & Chief Engineer & 1 \\
\hline \multirow[t]{2}{*}{ Professional Engineer } & Yes & 10 \\
\hline & No & 1 \\
\hline \multirow[t]{3}{*}{ Years in Industry } & $<10$ & 2 \\
\hline & $10-25$ & 4 \\
\hline & $>25$ & 5 \\
\hline
\end{tabular}

\section{Analysis}

We use Kingdon's theoretical framework [8] to analyze the technology assessment and adoption practices of the highway construction industry through a case study of IC. The framework generally applies well to the IC case study; however, coincident with the literature, the specific application of Kingdon's theory to the IC policy environment does reveal certain limitations. In tandem with Kingdon's framework, we consider responsible technology assessment concepts, e.g., ethical motivation and technological governance, with respect to IC diffusion and adoption within the highway construction community.

First, this research identifies the importance of personal character among key players, with respect to both problem definition and innovative championship. Second, regulation with state and federal departments of transportation (DOT) is a highly technical policy making environment, resulting in some deviation from Kingdon's original formulation. Third, while we found policy entrepreneurs to exist at all 
levels of the policy making environment, this research found the most predominate roles to be internal to a DOT. We find policy entrepreneurs to posses ideologies congruent with RRI literature, providing an opportunity to draw on these two frameworks simultaneously. Finally, we address certain limitations in applying Kingdon's theory to the joining of the three streams in the DOT regulatory environment. Contrary to Kingdon's general theory, we identify a tight coupling between the problem and policy streams in the case of IC diffusion at all times, rather than solely during the formation of policy windows. We also address the prevailing path by which IC policy is ultimately raised to the decision agenda.

\subsection{Personal Character}

The personal character of key players and stakeholders critically impacts innovation diffusion and acceptance in the IC policy environment. Kingdon [8] notes that personal character may play a role in explaining the motivations of policy entrepreneurs. However, we found this theme to run much deeper. Not only is personal character paramount in explaining the behavior of policy entrepreneurs, but it also defines ideological affiliations of participants in the political stream. Kingdon's theory minimally explores of the powerful impact of personal character, and its prevalence here is perhaps unique to the highway construction sector in which there is a distinct lack of external motivators for participants.

This section discusses how personal character applies to individuals in the network. Of particular importance is the degree to which individuals possess an intrinsic proclivity towards innovation. Furthermore, policy entrepreneurs demonstrate extremely unique personal quality by challenging the status quo, often enduring personal and professional risk to promote innovation. RRI speaks of the expanding occupational responsibilities of technologists to evaluate the societal benefits and risks of innovations [15]. Are individuals with a proclivity for innovation merely risk prone, or are they striving for the ethical guidelines being pioneered in RRI literature [15]? This research indicates that, regardless, an individual's intrinsically felt obligation to improving societal quality stems from personal character, even in the face of significant risk or obstacle. In the following section, DOT Regulatory Environment, we discuss personal character in the more general context of the political environment.

Project level implementation of IC is very specific to the personal character of the participants involved. Personal character impacts how, and if, the problem is defined depending on whom is being asked. This study reveals that general tendencies toward innovation appear to be truly sustained at the personal level. This study ultimately identifies the importance of personal character over institutional character, with respect to both problem definition and innovation championship.

\subsubsection{Innovation Proclivity}

Nearly all participants in this study identified innovation proclivity as a critical driver to the acceptance of IC diffusion. Many study participants further related this characteristic to an individual's 
outlook on change in general. One participant stated, "Personalities, one word...", when asked to comment on DOT climates that may foster or hinder innovation. There were references to individuals that were either innovators or "sticks in the mud". While there is likely to be a much smoother gradation of a person's level of innovation proclivity, this personal characteristic was a central theme.

In the case study on IC, there is hardly a clear distinction between a "situation" and a "problem". An individual's innovation proclivity impacts this distinction. In the case of IC, this personal characteristic can even serve as a more critical decision making factor than exposure to technical and visual evidence of performance improvements. In fact, one participant indicated that often times personal character can outweigh technical research and field validation of IC with disinterest and lack of acceptance. This statement indicates that, at least for some individuals in decision making for technology adoption, institutional inertia can be a stronger driver than the ethical criteria of societal benefit that an RRI framework places on technical decisions. At the very least, one's innovation proclivity impacts the way they interpret policy alternatives and problems, not to mention what values they base their decisions upon.

What makes an individual tolerant of innovation and risk? To answer this, we can leverage the large body of literature concerning innovation. Our study found a positive correlation between level of education and proclivity towards innovation, with $100 \%$ of participants with advanced degrees having specific examples of supporting an innovation. This concept concurs with prevailing literature, which suggests that individuals with an advanced structural organization of knowledge are better innovators [33]. We did not find any correlation between age and innovation, further supporting claims that innovation tendency is independent of age [33]. In interviews, supporters of innovation were often described as capitalizing on membership to sizeable professional networks, which agrees with research that shows a statistically significant correlation between one's personal network and diffusion of innovations in housing construction regulation [34]. Interviewees particularly emphasized the role of professional networks in providing exposure to a variety of ideas and demonstrations, and commanding a degree of credibility contributing to the capacity to spread ideas.

In addition, this research has identified cases where participants claimed to be innovative and open to new technologies such as IC, yet the practical reality appeared otherwise. No participant was, however, an explicitly, self-proclaimed hindrance to innovation.

\subsubsection{Policy Entrepreneurs}

Of the incentives for policy entrepreneurs that Kingdon discusses, the most pertinent to IC policy is that of values promotion. The policy entrepreneurs identified in this study had no personal gain from the success of IC and did not appear to be "policy groupies" ([8], p.123). Beyond Kingdon, we identify this type (i.e., values promotion) of policy entrepreneur to reflect RRI ideologies, in that they exemplify 
an ethical motivation to provide the most progressive and appropriate products and policy to society. This sense of social responsibility can be seen in their perseverance in the face of significant institutional inertia and lack of personal benefit .

Most important to understanding ideological stances, we look at motivation. An individual's stance on innovation and risk can be motivated either intrinsically or extrinsically. A study surveying eight DOTs found that the institutional incentives for innovation consisted solely of recognition [35]. Incentives that were mentioned included recognition in newsletters, and notoriety from technical conferences. Study participants reported that these extrinsic incentives do not drive policy entrepreneurs. Participants resoundingly attributed personal character, i.e., intrinsic motivation, as the dominant catalyst for policy change. Interviewees described champions of innovation as risking their short-term performance goals and professional reputations. One participant said of innovating, "You're swimming up Niagara falls, and your reputation is on the line". Yet, these individuals are the key to developing the political stream, and are active proponents of RRI principles.

\subsection{DOT Regulatory Environment}

The structure of the DOT has specific implications on Kingdon's theory. The DOT regulatory environment is referred to herein as a scientific bureaucracy [9]. So-called scientific bureaucracies are said to privilege scientific research as the basis for bureaucratic policy output [9]. We find this feature to significantly impact the implementation of socially responsive innovation in two ways. Firstly, rather than political affiliations, which Kingdon discusses as the most relevant ideological affiliation guiding agenda setting, we found participants identified themselves along lines of their proclivity for innovation. In this regulatory environment, we found this proclivity for innovation to be deeply rooted in participants' perceived sense of social obligation. Secondly, the heavy weighting of scientific research in the decision making process creates additional barriers to societal feedback. For example, where Kingdon finds political appointees to have a strong influence on agenda setting, in DOTs we find career bureaucrats, with no explicit societal representation, to hold the majority of power and resources over regulatory reform. Further, this regulatory environment exemplifies the fact that senior policy makers work at some distance from the actual decision-making process at the regional level regarding the choice of innovative technologies and new organizational processes [36].

\subsubsection{Ideological Affiliation}

Proclivity to innovation and risk taking are the most relevant ideological affiliations to this case study, as opposed to political party as discussed by Kingdon [8]. Individuals throughout the network can either contribute to or impede the progress of a policy change related to IC. In interviews, the innovation proclivity characteristic appeared to be the strongest indicator of their support for adoption. The 
dominance, or lack thereof, of this ideology can vary highly from state to state, and within different networks in the same DOT. Changes in the political makeup of a DOT network depend primarily on turnover of positions. Some participants felt that long term shifts in political makeup were occurring due to promotion criteria and practices. While this phenomenon seems possible, studying these changes was beyond the scope of this study, and would be worth further consideration.

Personal ideology underlies the discussion not just on innovation proclivity, but an individual's perceived societal obligation as well. As previously mentioned, policy entrepreneurs within the DOT regulatory environment appear to operate without expectation of personal gain. Instead, they are compelled by a sense of ethical responsibility to provide society with the most progressive and appropriate product and/or policy, despite significant institutional inertia and potential risk to their professional reputation.

\subsubsection{Bureaucrats vs. Political Appointees}

Kingdon stresses the role of political appointees in defining the political environment, suggesting the existence of a top down power structure: "the appointees, not the career civil servants, are the movers and shakers" ([8], p30). Our findings, however, indicate that this model for federal policy agenda setting differs considerably from state transportation construction policy agenda setting. None of the study participants indicated the influence of the politically appointed DOT directors to be a significant factor in IC adoption, or innovation in general. DOT regulatory reform appears to occur outside the influence of appointed positions and in fact, civil servants tend to operate as policy entrepreneurs.

This agenda setting structure is perhaps due to the highly technical nature of infrastructure construction. Specialists, in the form of civil servants, are disposed with more agenda setting power than appointees. Yet some DOTs are clearly the front runners in use of IC, suggesting the presence of unique conditions at these DOTs. Identifying the institutional positions within which these entrepreneurs act is the first step in understanding a political environment.

We propose a method for identifying a DOT's ideological distribution through a classification system based upon participant interviews. The manner in which a political environment becomes conducive to policy change involves strategic, albeit serendipitous, positioning of four key roles presented in Figure 1. First, there are "policy explorers" that manifest problem awareness and demonstrate technical feasibility, often having to battle institutional inertia. Interviews revealed these individuals to exist as DOT research engineers, DOT district engineers, and construction contractors. For an innovation to proceed to the next level, explorers must make a successful hand off to "policy pioneers". Pioneers are individuals willing to expend political leverage, energy and resources to implement a new technology, such as IC, on DOT projects. This entails passing a special specification for the project, requiring political influence that can typically only be exerted by a DOT District Engineer or a contractor. Special 
specification passage generally requires an iterative interchange between the these two key roles, i.e., explorers and pioneers.

Figure 3. Pathways to Innovation Adoption. Depiction of three of the four roles required for innovation adoption in highway construction: explorers research potential innovations; pioneers apply promising innovations on projects through special specifications; and gatekeepers determine if an innovation is suitable for statewide use. The fourth role, leaders, help to coordinate and motivate the interactions of the other roles.

Upon successful implementation of the innovation via the special specification, it can be considered for full adoption by the gatekeepers, whom often sit on a specification review committee. Gatekeepers provide a final interpretation of the overall innovation adoption impact to aid in the specification reform process. Specification review committees vary in composition between states, but often include chief engineers and division engineers. Gatekeepers also include certain outside organizations, including funding agencies (e.g., FHWA) and professional organizations (e.g., AGC) that that participate in the specification review process. Finally, there must be leaders willing to endorse an unaccepted technology via a vast political network. Leaders are critical in coordinating and motivating the hand-off between the aforementioned levels. This power anecdotally resides in high ranking management positions. When there is ideological alignment of individuals in exploring, pioneering, gatekeeping, and leadership roles, the political stream is ripe for innovation-based policy agenda setting.

The four roles described in this section encompass all the policy pathways that were identified through our case study. The roles mirror the three phases of the reform process, namely, research, special specification, and statewide specifications, and the overarching role of leader. If other phases or policy pathways exist, there may be other roles. Further case studies, especially in the transportation and construction industries, would be helpful in assessing the existence of other pathways and roles. Regardless, these four roles may provide a useful framework for policy makers to improve DOT operations via the pathways we have established.

It is conceivable that this framework may extend to regulatory reform in other cases. We anticipate that this framework is most likely to apply to scientific bureaucracies that rely heavily on evidence based rule making, such as when pilot deployments or demonstrations are critical steps to gaining acceptance and achieving adoption. As this case study represents an extension of Kingdon's theory to the state level, it is unclear what limitations may exist in applying this framework to federal and other levels of government. For example, we identified State DOT regulatory reform as being dominated by career bureaucrats, whereas Kingdon identifies political appointees being the most influential in federal policymaking. Future work exploring the applicability of the four roles identified here to other levels of government would contribute to this analysis. 


\subsection{Key Roles of Policy Entrepreneurs}

Coincident with Kingdon's theory, policy entrepreneurs can exist at any level or position within the political environment surrounding IC. However, the vast majority of policy entrepreneurs identified by participants in this study were DOT employees. This research has specifically identified policy entrepreneurs within a DOT in the roles of research engineers or district level engineers. These employees possess the resources to build support and ultimately promote the subject to a level of authoritative decision and specification. External contractors have also been carriers who brought IC into a project at their own interest and expense, but this appears to be the exception. Surprisingly, the IC equipment manufacturers, who perhaps have the most to gain from a policy change, appear to have no direct representation in the form of a policy entrepreneur.

The most common source of problem identification is via internal promotion within a governmental agency, be it a state DOT or federal authority. This research has identified policy entrepreneurs at various levels within both state and federal organizations. Whether a research engineer or district manager, all study participants indicated the necessity for policy entrepreneurs to bring the problem to the attention of key players. Entrepreneurs are responsible for actively raising awareness to convince colleagues in positions of power that IC was an endeavor worthwhile.

Research and district level engineers are each dispatched with distinct powers that enable them to be effective policy entrepreneurs. Research engineers are the technical experts of the DOT organization, making them a collection point for technical problems in the organization and giving them the credentials to suggest solutions to individuals across the DOT. Furthermore, these individuals are given funds to conduct research, including pilot projects, which we have identified as a key mechanism for spreading problem awareness and getting support for policy solutions. Research engineers are able to leverage their credentials and funds, in combination with their professional networks, to couple the problem and policy streams.

District level engineers possess considerable decision making power due to the decentralized nature of DOTs. Respondents unanimously agreed to the near autonomy of districts in conducting their projects. One interviewee said "the district is the customer," implying the central office provides services to the districts as opposed to managing them. If a district engineer decides he wants to use an innovation on a project, he holds the political power to put related policy issues on the agenda. Specifications still need to be approved by a committee that may contain other district engineers and high ranking officials in the central office, but the agenda setting for special specifications is controlled at the district level.

Policy entrepreneurs may also be external to the governmental agency, residing at the level of external contractors. In sparse cases, a contractor has taken initiative to suggest or integrate usage of IC on a specific project. As mentioned, the motivation here is achieving improved quality and/or cost 
efficiency. For example, one respondent cited a contractor using IC to provide additional as-built construction documentation in the advent of future litigation. Regardless of specific motivation, this form of diffusion appears less common without mandate or specification due to lack of incentive. In addition, self promotion of IC use tends to be a luxury reserved for larger contractors responsible for larger projects.

Surprisingly, we did not identify any policy entrepreneurs from equipment manufacturers. It would seem that these companies would stand much to gain from IC reaching the decision agenda, thereby increasing market penetration. Representatives of manufacturers (and their dealers) seem to almost exclusively court contractors with this technology, despite the importance of DOT buy-in. It is worth noting that equipment manufacturers will contribute equipment and engineering time to pilot projects, but this typically results from partnerships with contractors or researchers. Their lack of interest in the policy realm appears a function of their business model, which does not promote interaction with governmental bodies.

\subsection{Joining of the Streams}

Kingdon discusses the confluence of streams as policy windows, critical points in advancing policy issues when an opportunity for the issue to reach the decision agenda exists. Yet, in our case the policy and problem streams are coupled very early in the process by policy explorers (and sometimes others). The political stream is often the last stream to join, resulting in what Kingdon identifies as politically activated policy windows [8]. The joining of the political steam, and thus the opportunity for the issue to reach the decision agenda, is conducted by policy pioneers (discussed in the "bureaucrats vs. political appointees section").

\subsubsection{Problem and Policy Stream Coupling}

Pilot studies are the mechanism by which problem and policy streams become coupled. While the development of either of these streams may occur independently through other mechanisms, participants reported pilot studies as the predominant method for building both streams. The research aspect of pilot projects provides policy recommendations by establishing the technical validity of various implementations. Pilot projects often simultaneously invite members of the policy community for field demonstrations, which give firsthand experience that is particularly poignant in punctuating the problem to individuals. This tight coupling of problem and policy streams is not recognized in Kingdon's book [8], and may be a feature specific to highway construction.

We identify policy entrepreneurs and their critical role in punctuating the problems and promoting policy solutions connected with IC. The primary task for them becomes building awareness and the dissemination of knowledge and information to initiate the problem stream and couple the policy 
stream. This task is crucial to establish the status quo and its disconnect, or problem, with what improvements could be made through use of IC.

Field demonstrations were reported by all study participants as the most effective way to illuminate a problem and spread solution awareness. Field demonstrations provide direct empirical evidence of the potential improvements that a new technology such as IC can provide. Field demonstrations occur at various project levels. Despite the disjoint nature of state DOT operations, several participants were introduced to IC through field demonstrations both locally, nationally or internationally. International delegations, comprised of federal and state DOT employees, industry contractors and academics, perform scan tours to become exposed to new technologies in other parts of the world. This is particularly true in the case of IC, as the European highway community readily began research and development as early as the 1970s. European attention was undoubtedly a platform to foster U.S. interest in IC according to study participants. At the local or national level, several policy entrepreneurs within and even across state DOTs have diligently organized field demonstrations to raise awareness and garner support for IC.

In all cases, direct exposure to IC has been reported to be highly successful in coupling problem punctuation with policy solutions. One participant noted that direct exposure via field demonstrations brings a certain concrete interaction and awareness that is difficult to achieve by simply reading technical reports or specifications. Another participant recalled a rather telling response of a DOT official following an IC field demonstration: "Wow, I didn't realize...and I guess it's a no brainer, we ought to do this...", and thus establishing the problem stream for IC in mind. Only once an idea takes hold in people's minds can it become institutionalized as policy reform [10].

\subsubsection{Political Stream Coupling: Opening of Policy Windows}

According to Kingdon [8], issues reach decision agendas when the three streams are joined through a transformation in the political stream or novel problem identification. We define IC as 'reaching the decision agenda' when its usage on a project is suggested by either the DOT or a contractor resulting in initiating formation of a special specification. No states currently have a statewide specification for IC, so this case is not considered. This section discusses various aspects of the opening of policy windows. Our research shows that the joining of streams happens predominantly through politically activated windows. The individuals responsible for opening the policy window are policy pioneers (discussed in the "bureaucrats vs. political appointees section"), who are typically district engineers. In rare instances, these policy pioneers could be external to the government, but this appears to be contingent on the contractual structuring of the project. We also discuss specific economic aspects of the IC technology that impact the opening of policy windows. 
In the case of IC, proper alignment of ideologies between the four key roles discussed in the DOT Regulatory Environment section provides a critical window of opportunity. The key roles of exploring, pioneering, gatekeeping, and leadership represent the minimum support structure necessary to pass new specification. The problem and policy streams already pose a tight coupling in this industry. A political alignment is necessary because policy changes require individuals to place themselves at risk, which they will not do without an understanding that the necessary support exists.

Of particular note in this network is the role of policy pioneers, who again are the ones that exert their influence to formulate the use of IC on a project. These individuals' reputations are directly attached to the projects they work on, and we must stress the overwhelming sentiment of respondents that failure carries a much higher consequence than success. Study participants listed the most common position of IC policy pioneers to be in state DOT district offices, i.e. the ones in charge of executing the majority of highway construction and maintenance projects. The second most common position of policy pioneers for IC is engineers within general contracting firms. Policy pioneers can exist elsewhere within the DOT, including engineers overseeing special projects from a position in the DOT central office. Participants noted that in very rare cases, pioneers have been positioned in the FHWA and AGC, using political power to initiate policy reform.

Upon the opening of this politically activated policy window, it appears that the tight coupling of the policy and problem streams facilitated a rise of IC to the decision agenda. Field demonstrations provide this tight coupling and are used as a networking event where problem and policy streams are simultaneously illuminated to political participants. As one participant put it, "we had all the right people at the field demonstration. The ones [district engineers] that were interested were easily able to identify potential projects in their districts."

Interestingly, our study only found contractors as policy pioneers on Design-Build (DB) projects. $\mathrm{DB}$ is a contracting structure in which the contractor is responsible for designing the structure. This is in contrast to the more typical Design-Bid-Build (DBB), in which the design phase is conducted by another entity. Two aspects of contracting appear to make DB better suited for supporting contractor initiated innovation: award criteria and control over design. The awarding criteria for DBB projects is typically lowest cost, while DB often supports best-value evaluation. DB provides the opportunity for contractors to consider innovations like IC that provide added value at an added cost. Another advantage of DB is that it allows contractors to discuss novel ideas early in the design phase. This is critical for technologies like IC that impact the design of the structure through soil selection and placement guidelines. The DB structure expands the window of opportunity for contractors to act as policy pioneers and bring an issue to the policy agenda. 
The up-front investment for a technology is also a critical factor in understanding the formation of viable policy windows. Multiple interviewees provided non-IC examples where contractors could often be more effective at implementing innovations at municipalities because there was a closer working relationship and less bureaucracy. However, innovations with a high initial investment, such as IC, would be unlikely candidates to appear first on small municipal projects. Implementation of these types of technologies therefore depends more heavily on the innovation-based policy reform practices of state DOTs discussed in this paper.

\section{Conclusion}

U.S. DOTs face a tough road ahead with constricting budgets and deteriorating highway conditions. Technological innovation is one means to alleviate this pressure, but the highway construction industry is notoriously slow at adopting new innovations. In this paper, we have sought to understand this innovation adoption process through Kingdon's theory of agenda setting and in the context of responsible technology assessment and adoption processes. Our intention was three-fold: (1) to provide insights into DOT policy reformation processes that we hope the industry will find useful in creating robust technology assessment and adoption practices, (2) to add to the body of literature on responsible technology assessment and adoption by contributing a case study from the highway construction industry, and (3) to investigate the applicability of Kingdon's theory of agenda setting to an industry that is highly technical, risk averse, and bureaucratically decentralized. This paper highlights four critical points regarding the responsible assessment and adoption of innovations in the highway construction industry, specifically in the case of IC.

First, perhaps the most critical factor driving technology assessment and adoption is the personal character of the people involved; their risk tolerance and perseverance are what give an innovation a chance at adoption. This research identifies the importance that personal character plays in a general sense, i.e., with respect to an innate tendency of personnel in this industry to either accept or reject innovation. Coincident with the literature, personal character is duly noted as one of the primary motivators for policy entrepreneurs. Policy entrepreneurs in this industry appear to be of Kingdon's values promotion category, exemplifying an ethical motivation to responsibly serve society with the most progressive and appropriate technological innovations. This ideology is congruent with RRI literature, providing an opportunity to bridge and concurrently apply Kingdon and RRI frameworks. Analysis revealed that institutional incentives for supporting innovations were not the main drivers for adoption, and there exists a conservative culture that hinders change.

Second, the highly technical nature of DOT policy making creates a challenging environment for including societal feedback. This feature complicates the interpretation of Kingdon's original presentation of his framework. This technical policy environment results in a need to redefine ideological affiliations 
as a proclivity towards innovation, i.e., rather than political affiliation. Further, this environment promotes a reversal of Kingdon's idea that political appointees catalyze change, as opposed to civil servants. Instead it is clear that it is the career civil servants that need to be the movers and shakers for regulatory reform. In future applications of Kingdon's framework, the role of bureaucrats in agenda setting should be evaluated on a case-by-case basis.

Third, we expand upon Kingdon's idea of policy entrepreneurs so far as to define four roles these entrepreneurs fulfill in the DOT technology assessment and adoption process, namely the policy explorers, policy pioneers, gatekeepers, and leaders. The identification of these roles may assist DOTs in creating more robust assessment and adoption practices through the alignment of these individuals. We suggest that future research investigates whether these roles generalize to other institutions.

Finally, rather than the convergence of the three streams at a single policy window as Kingdon suggests, we identify a tight coupling between the problem and policy streams that precedes IC reaching the decision agenda. This is in agreement with other literature that draws into question the dynamics of Kingdon's stream coupling [9]. Kingdon's theory is, however, useful in addressing the prevailing path by which IC policy is ultimately raised to the decision agenda via a politically activated window. Stream coupling plays a defining role in policies reaching the decision agenda. In the case of IC, field demonstrations appear to be an effective mechanism for coupling streams suggesting that these efforts are crucial to innovation adoption.

It is our hope that these contributions will provide tools that help manage responsible research and innovation adoption in the highway construction industry.

\section{Acknowledgements}

This work was sponsored in part by NSF IGERT Grant DGE-0801692. The authors would like to thank Michael Mooney for offering his expertise on highway construction and Intelligent Compaction technologies. Our appreciation goes out to Carl Mitcham for his insights on responsible research and innovation. The authors are grateful for all the interview participants that agreed to take part in this study.

\section{References}

[1] American Association of State Highway and Transportation Officials, "Rough Roads Ahead: Fix Them Now or Pay for it Later," Washington D.C., RRA-1, 2009.

[2] M. Wachs, "Improving Efficiency and Equity in Transportation Finance," Second National Conference on Transportation Finance, Washington D.C., 2001, p. 215.

[3] P. Barrett, C. Abbott, M. Sexton, and L. Ruddock, "Hidden innovation in the construction and property sectors," RICS Res. Pap. Ser., vol. 7, no. 20, pp. 1-21, 2007.

[4] T. Hellstrom, "Systemic innovation and risk: technology assessment and the challenge of responsible innovation," Technol. Soc., vol. 25, no. 3, pp. 369-384, aug. 2003. 
[5] T. Daim, D. Yates, Y. Peng, B. Jimenez, "Technology assessment for clean energy technologies: The case of Pacific Northwest," Technol. Soc., vol. 31, no. 3, pp. 232-243, Aug. 2009.

[6] G. Assefa, B. Frostell, "Social sustainability and social acceptance in technology assessment: A case study of energy technologies," Technol. Soc., vol. 29, no. 1, pp. 63-78, Jan. 2007.

[7] P. Kalbar, S. Karmaker, S. Asolekar, "Technology assessment for wastewater treatment using multiple-attribute decision making," Technol. Soc., vol. 34, no. 4, pp. 295-302, Nov. 2012. [8] J. Kingdon, Agendas, Alternatives, and Public Policies, Second. New York, NY: HarperCollins, College Publishers, 1995.

[9] S. Harrison, M. Moran, and B. Wood, "Policy emergence and policy convergence: the case of 'scientific-bureaucratic medicine' in the United States and United Kingdom," Br. J. Polit. Int. Relat., vol. 4, no. 1, pp. 1-24, 2002.

[10] P. John, "Is There Life After Policy Streams, Advocacy, Coalitions, and Punctuations: Using Evolutionalry Theory to Explain Policy Change?," Policy Stud. J., vol. 31, no. 4, pp. 481498, 2003.

[11] B. Kelly, "John Kingdon's Theory at the State Level: A Look at Preschool for All in Illinois and California," 2005.

[12] Texas Department of Transportation, "Organizational charts for each division and district," Austin, Texas, May 2000.

[13] T. Zayed, M. Amer, J. Pan, "Assessing risk and uncertainty inherent in Chinese highway projects using AHP," Int J Project Manag, vol. 26, no. 4, pp. 408-419, May 2008, ISSN 02637863.

[14] M. Geoghegan-Quinn, "RRiGEM Responsible Research and innovation and how it affects iGEM: RRI. A new approach of ethicsin science.," Eur. Commision Res. Innov. Sci., pp. $1-12$, unknown.

[15] R. von Schomberg, "Organizing collective responsibility. On precaution, codes of conduct and understanding public debate," in Keynote lecture at the meeting of the Society for the Study of Nanoscience and Emerging Technologies, Seattle, 2009.

[16] B. K. Sovacool, "The cultural barriers to renewable energy and energy efficiency in the United States," Technol. Soc., vol. 31, no. 4, pp. 365-373, Nov. 2009.

[17] Kimmel, S., Toohey, N., \& Delborne, J. (2015). "Innovation at the Crossroads: Exploring the Intersection of Innovation Adoption and Specification Reform in Public Highway Construction." in Transportation Research Circular, vol. E-C199, pp. 9-18. Washington, D.C.: Transportation Research Board.

[18] P. A. Sabatier, "Toward Better Theories of the Policy Process," Am. Polit. Sci. Assoc., vol. 24, no. 2, pp. 147-156, 1991.

[19] M. Cohen, J. March, and J. Olsen, "A Garbage Can Model of Organizational Choice," Adm. Sci. Q., vol. 17, pp. 1-25, Mar. 1972.

[20] J. DeJong-Hughes, J. F. Moncrief, W. B. Voorhees, J. B. Swan, "Soil Compaction: Causes, Effects, and Control." Accessed March 20, 2014, url:

http://www.extension.umn.edu/agriculture/Tillage/soil-compaction/index.html

[21] Mechanistic-Emperical Pavement Design Guide: A Manual of Practice, July 2008 Interim Edition. Washington D.C.: AASHTO, 2008.

[22] "ASTM D698 - 07e1, Standard Test Methods for Laboratory Compaction Characteristics of Soils Using Standard Effort (12 $400 \mathrm{ft}-\mathrm{lbf} / \mathrm{ft} 3$ (600 kN-m/m3)).” ASTM International, West 
Conshohocken, PA, 2007.

[23] H. F. Thurner, "Quality Assurance and Self Control in Road Construction, Advanced Measurement Technology," Geodyn. AB, p. 11, 2001.

[24] T. Cackler, "Soil Compaction Monitoring Technology, tech transfer summary,"

Partnersh. Geotech. Adv. Iowa State Univ., vol. 6, no. 2, pp. 148-155, 2004.

[25] M. A. Mooney, R. V. Rinehart, D. J. White, P. Vennapusa, N. Facas, and O. Musimbi, "Intelligent Soil Compaction Systems," Transportation Research Board, Washington D.C., NCHRP Report 676, 2011.

[26] D. White, M. Thompson, K. Jovaag, E. Jaselskis, V. Schaefer, and T. Cackler, "Field Evaluation of Compaction Monitoring Technology: Phase II," Center for Transportation Research and Education, CTRE Pr oject 04-171, 2006.

[27] G. Chang, Q. Xu, J. Rutledge, B. Horan, D. White, and P. Vennapusa, "Accelerated Implementation of Intelligent Compaction Technology for Embankment Subgrade Soils, Aggregate Base, and Asphalt Pavement Materials," Federal Highway Administration, FHWA IF - 12 - 002, 2011.

[28] US FHWA, "Intelligent Compaction Technology for Soils Applications.” Sep-2012.

[29] Transportation Research Board, "Building momentum for change: creating a strategic forum for innovation in highway infrastructure," National Research Council, Special Report 249, 1996.

[30] “2011 CDOT Field Materials Manual.” Colorado Department of Transportation, 2011. [31] V. Blackman, "Putting Policy Theory to Work: Tobacco Control in California," Policy Polit Nurs Pr., vol. 6, no. 2, pp. 148-155, 2005.

[32] H. L. Schachter, "Successful Transportation Women in a Time of Downsizing," Public Adm. Q., pp. 460-481, 2004.

[33] L. Shavinina and K. Seeratan, "On the Nature of Individual Innovation," in The International Handbook on Innovation, Elsevier Science Ltd., 2003, pp. 31-33.

[34] S. M. Oster and J. M. Quigley, "Regulatory barriers to the diffusion of innovation: Some evidence from building codes," Bell J. Econ., pp. 361-377, 1977.

[35] CTC \& Associates LLC, "Developing a Culture of Innovation," MnDOT, TRS 1003, Feb. 2010.

[36] D. Gann, "Should governments fund construction research?," Sci. Policy Res. Unit, vol. 25, no. 5, pp. 257-267, 1997. 


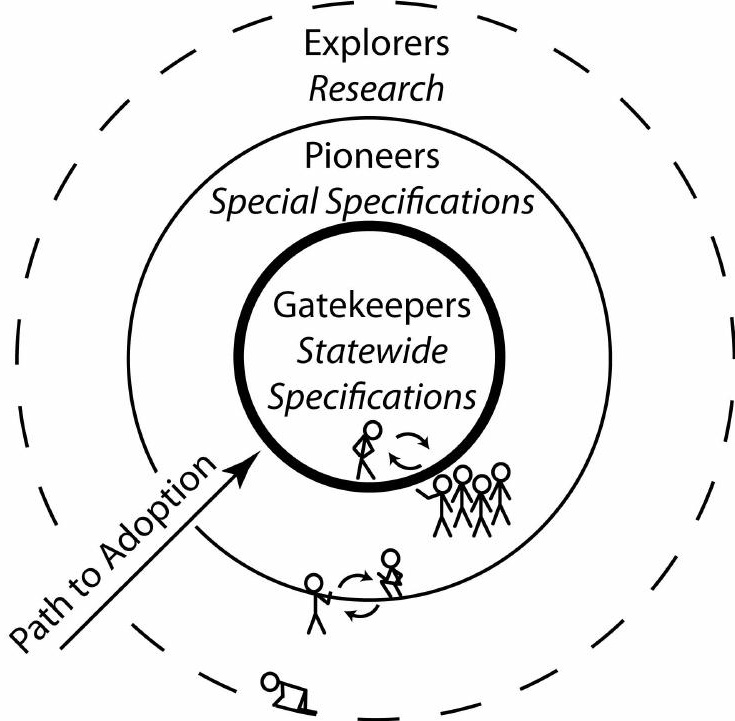




\section{State \\ Director (Appointed)} DOT

Chief Engineer

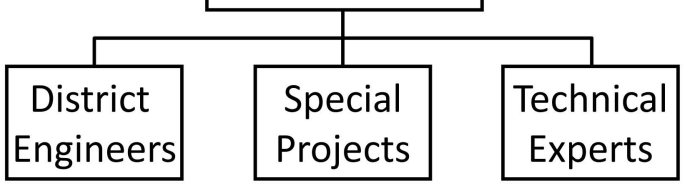

Construction

Quality

Dictated

via Spec.
Spec.

Formation

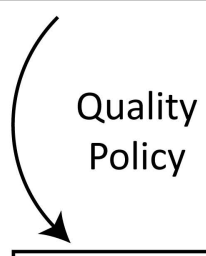

Construction

Contractor
Critique

Spec.

Formation

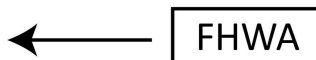

(Funding)

AGC
(Interest

Group) 

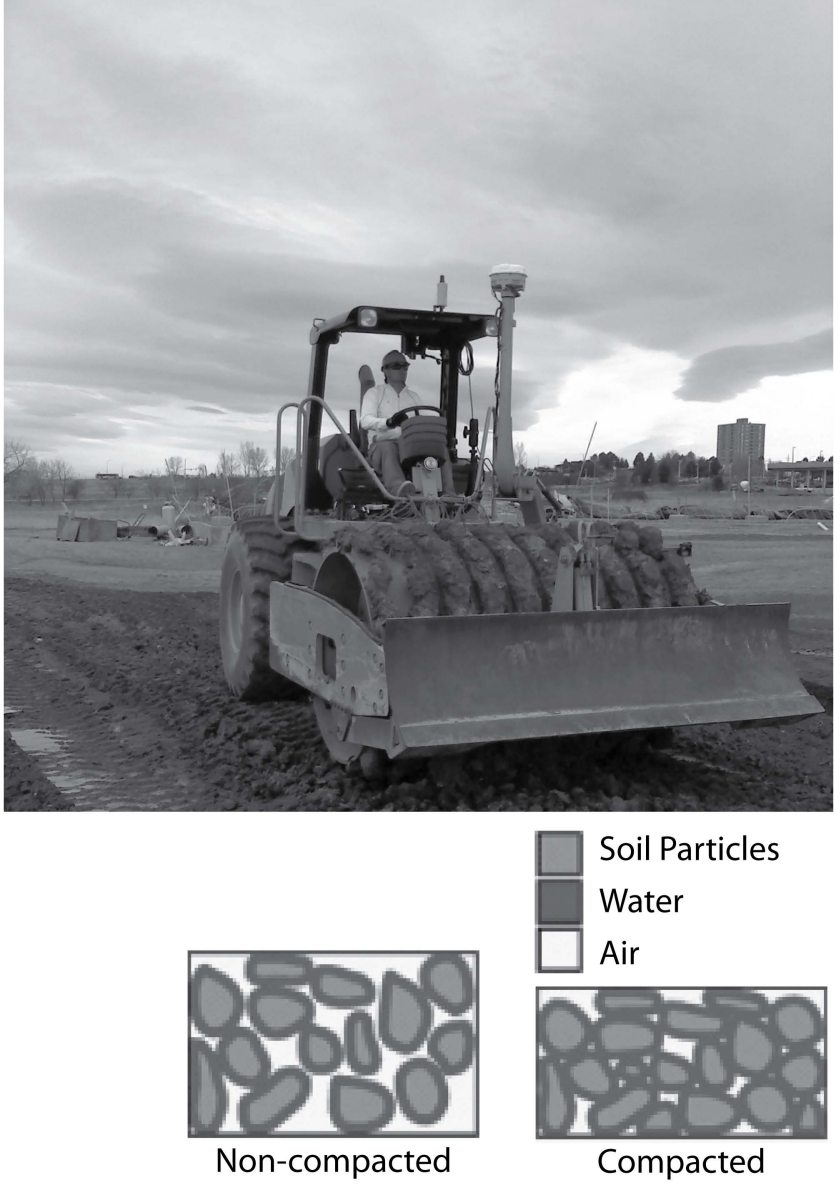